\title{
INVENTÁRIO DE EMISSÕES VEICULARES DO MUNICÍPIO DE MANAUS
}

\author{
C. L. PINHEIRO ${ }^{1}$, K. L. S. DA ROCHA ${ }^{1}$ e D. G. DOS SANTOS ${ }^{1}$ \\ ${ }^{1}$ Universidade do Estado do Amazonas, Bacharelado em Engenharia Química - EST \\ E-mail: cpinheiro@uea.edu.br
}

article info

Article history:

PALAVRAS-CHAVE: Inventário de Emissões; Poluição Atmosférica; Manaus; Emissões Veiculares; Poluentes.

Received 20 May 2016

Accepted 3 January 2017

Available online 27 July 2017

RESUMO: Um inventário de emissões é útil para estudar as emissões gasosas em uma área durante um periodo. Com ele pode-se identificar fontes de emissão e, assim, propor estratégias de controle da qualidade do ar. Este trabalho apresenta um inventário de emissões veiculares para Manaus. As fontes foram veículos divididas em: automóveis (A), comerciais leves (CL), veículos pesados (VP) e motocicletas (M). Nos cálculos do inventário, considerou-se: tipo de combustível, idade da frota e distância anual média percorrida. Os automóveis a gasolina apresentaram emissões de monóxido de carbono (CO), aldeídos e óxidos de nitrogênio (NOx) de 11.294; 16,4 e; 4.274 ton/ano, respectivamente. Nos CL a gasolina, a emissão de hidrocarbonetos (HC) foi de 178 ton/ano. As motos tiveram emissões expressivas de CO e HC com 1.829 e 178 ton/ano, respectivamente. Os VP tiveram as maiores emissões de NOx e MP (material particulado). Estas informações são úteis no estudo de dispersão atmosférica e para órgãos ambientais.

\section{INTRODUÇÃO}

Desde os tempos antigos, a humanidade vem aprimorando suas atividades produtivas e, com elas, podendo obter grandes avanços, como melhorias na qualidade de vida da população e avanços tecnológicos. No entanto, concomitante ao progresso obtido nas atividades humanas, observou-se um crescimento nos níveis de poluição, principalmente com o aumento da produção industrial em consequência da geração de energia útil via combustão de derivados do petróleo, como gasolina, diesel, entre outros (Carvalho Jr e Lavaca, 2003).

Um dos recursos naturais mais afetados pela poluição é o ar atmosférico e a preocupação com a poluição deste vem aumentando devido ao crescimento das grandes cidades e ao aquecimento global. A poluição atmosférica inclui qualquer atividade humana ou natural que leve à deterioração da atmosfera e entre os principais poluentes, que afetam a qualidade do ar, estão: monóxido de carbono (CO), óxidos de nitrogênio (NOx), hidrocarbonetos $(\mathrm{HC})$, ozônio $\left(\mathrm{O}_{3}\right)$, dióxido de enxofre $\left(\mathrm{SO}_{2}\right)$, dióxido de carbono $\left(\mathrm{CO}_{2}\right)$ e material particulado (MP). Estes poluentes em zonas urbanas são emitidos por duas principais fontes: as fixas (queimadas, indústrias, etc.) e as móveis (veículos automotores, aviões, helicópteros, etc.), onde a segunda é responsável pela maior parte das emissões 
devido ao grande número destas nos centros urbanos (Baird, 2002; Carvalho Jr e Lavaca, 2003; Onursal e Gautam, 1997; Sher, 1998; Ueda, 2010).

Um inventário de emissões é uma ferramenta útil para a análise ambiental. A sua função é identificar a emissão de poluentes, suas fontes, quantidades e localizações. Ele pode ser feito a partir da compilação de dados referentes às concentrações de poluentes atmosféricos. Estas informações quantitativas servem como parâmetro para uma vasta gama de decisões que podem incluir o monitoramento das concentrações de poluentes na atmosfera, avaliação de riscos à saúde humana, identificação das áreas responsáveis pelas emissões, servir como dados de entrada em modelos preditivos da dispersão de poluentes atmosféricos, servir como base para tomada de decisões de contenção de problemas ambientais, entre outros (EEA, 2003; EMEP, 2007; Ueda, 2010; U.S.EPA, 1999).

Para o desenvolvimento de um inventário de emissões são tomadas duas abordagens. A primeira é a top-down e representa a estimativa de emissões a partir de dados abrangentes, como dados nacionais, que são escalonados para área de estudo. A segunda é a botton-up e representa emissões individuais e, quando somadas, podem servir de base para uma estimativa em nível regional ou nacional. Com relação ao método a ser empregado para elaborar o inventário, deve-se levar em conta as relações entre custo do método e a precisão das estimativas e dos dados obtidos, tendo em vista a finalidade do inventário, assim como o tempo e os recursos disponíveis (U.S.EPA, 2001).

Para o caso de fontes pontuais, geralmente emprega-se um método baseado em fatores de emissão, onde uma estimativa das emissões é realizada baseando-se na taxa de emissão do poluente por aquelas fontes. Além disso, embora este método não forneça dados reais, as estimativas dadas por ele são consideradas razoáveis e de baixo custo, pois bases de dados, fatores de emissão e equações matemáticas são utilizados (U.S.EPA, 2001).

Portanto, baseando-se no contexto acima e, além disso, na ausência de um estudo de quantificação de poluentes atmosféricos provenientes de emissões veiculares para Manaus (Amazonas, Brasil), o presente trabalho teve como objetivo elaborar de um inventário de emissões veiculares para Manaus, de modo a estimar as taxas de emissão de poluentes.

\section{MATERIAIS E MÉTODOS}

A abordagem utilizada para o desenvolvimento deste inventário foi a botton-up com fatores de emissão.

Os dados utilizados foram obtidos do site do Departamento Nacional de Trânsito (DENATRAN, 2014) e da Associação Nacional de Fabricantes de Veículos Automotores (ANFAVEA, 2014) para o ano de 2013 (ano base), sendo que a distribuição de idade da frota, o perfil da frota, o fator de deterioração em função da idade do veículo, as distâncias médias percorridas em função da idade do veículo e o tipo de combustível utilizado foram considerados para a elaboração do inventário e estimativa das taxas de emissão. 
Os veículos que compõem a frota de Manaus neste estudo foram agrupados em quatro classes: automóveis (AUTO), comerciais leves (micro-ônibus e camionetas) (CL), motocicletas (MOTO) e veículos pesados (caminhões, reboques, ônibus e outros) (VP), semelhante à classificação citada por Ueda (2010).

A Tabela 1 apresenta a quantidade de veículos novos licenciados no munícipio de Manaus em 2013 e a distribuição percentual desta quantidade. Essa distribuição de 2013 foi aplicada aos dados de veículos totais licenciados entre 1957 e 2012 em Manaus, de modo a estimar os números de veículos para cada ano em cada classe.

\begin{tabular}{ccc}
\multicolumn{3}{c}{ Tabela 1 - Composição da frota de Manaus por classe de veículo } \\
\hline TIPO DE VEÍCULO & $\mathbf{N}^{\circ}$ DE VEÍCULOS & $\mathbf{\%}$ \\
\hline AUTO & 22.687 & 53,54 \\
CL & 6.876 & 16,23 \\
VP & 2.928 & 6,91 \\
MOTO & 9.881 & 23,32 \\
TOTAL & $\mathbf{4 2 . 3 7 1}$ & $\mathbf{1 0 0 , 0}$ \\
\hline
\end{tabular}

Com a quantificação da frota para Manaus, foi possível calcular a taxa de emissão para os seguintes poluentes: monóxido de carbono (CO), hidrocarbonetos (HC), óxidos de nitrogênio (NOX), material particulado (MP) e aldeídos (RCHO), sendo que o mesmo método de cálculo foi utilizado nas quatro classes de veículos, conforme Ueda (2010).

As estimativas de emissões de material particulado foram consideradas apenas para veículos movidos a óleo diesel e as emissões de aldeídos apenas para automóveis e comerciais leves movidos a etanol.

A quilometragem acumulada da frota foi calculada por meio da Equação 1, onde: $v$ é a idade e $z$ a quilometragem acumulada.

$$
z=-367,87 v^{2}+13.664 v
$$

Com a quilometragem acumulada (z), calculou-se os fatores de deterioração dos poluentes monóxido de carbono $\left(\mathrm{FD}_{\mathrm{CO}}\right)$ e hidrocarbonetos $\left(\mathrm{FD}_{\mathrm{HC}}\right)$ por meio das Equações 2 e 3, sendo o fator $Y$ obtido através da Equação 4.

$$
\begin{gathered}
F D_{C O}=\frac{56,34+2,55 Y}{56,34} \\
F C_{H C}=\frac{4,43+0,25 Y}{4,43} \\
Y=\frac{z}{1,61 \times 10^{4}}
\end{gathered}
$$


$\mathrm{O}$ valor de $\mathrm{Y}$ foi constante e igual a 6,27 para veículos com mais de $100.000 \mathrm{~km}$ acumulados percorridos. Além disso, para os poluentes óxidos de nitrogênio $\left(\mathrm{NO} \mathrm{X}_{\mathrm{X}}\right.$, material particulado (MP) e aldeídos (RCHO), o fator de emissão (FC) foi considerado igual a 1 (MURGEL et al. 1987 apud UEDA, 2010).

$\mathrm{O}$ valor do fator de emissão corrigido (FE*) foi obtido multiplicando o fator de emissão para veículos novos, fornecido pela CETESB (2014) (FE), pelo fator de deterioração (FD). Assim: (FE* = FE x FD). Então, com o valor de FE*, calculou-se a taxa de emissão para cada idade da frota pela Equação 5 e a taxa de emissão total pela Equação 6.

$$
\begin{gathered}
\frac{\text { Taxa de emissão anual }}{\text { idade }}=\mathrm{n}^{\circ} \text { de veículos } \times \mathrm{km} \text { média anual } \times \mathrm{FE}^{*} \\
\text { Taxa de emissão total }=\sum_{\text {idade }}\left(\mathrm{n}^{\circ} \text { de veículos } \times \mathrm{km} \text { média anual } \times \mathrm{FE}^{*}\right)
\end{gathered}
$$

Para estimar a emissão dos automóveis (AUTO) movidos a gasolina e álcool, utilizou-se o fator de emissão corrigido e, para os automóveis bicombustíveis, utilizou-se fatores de emissão de veículos comerciais leves (CL) novos tipo flex-álcool (CETESB, 2014). Além disso, considerou-se que a quilometragem média anual percorrida por automóveis novos (ou seja, em 2013) foi de $20.000 \mathrm{~km}$ no primeiro ano de uso e, com o aumento da idade, aplicou-se uma taxa anual de redução da quilometragem igual a 2\% (ISSRC, 2008 apud Ueda, 2010).

Para estimar a emissão dos comerciais leves (CL), considerou-se veículos movidos a gasolina, a etanol, a diesel e os bicombustíveis, utilizando os fatores de emissão da CETESB (2014), exceto para os veículos movidos a diesel, onde utilizou-se os fatores de emissão de veículos pesados (VP). A quilometragem média anual percorrida por veículos comerciais leves novos (em 2013) foi de $36.500 \mathrm{~km}$ (UEDA, 2010) e, com o aumento da idade, aplicouse uma taxa anual de redução da quilometragem média igual a $2 \%$.

Para estimar a emissão dos veículos pesados (VP), considerou-se que todos estes veículos foram movidos a diesel com seus fatores de emissão obtidos de CETESB (2013). A quilometragem média anual percorrida por veículos pesados novos (em 2013) foi de 20.000 $\mathrm{km}$ no primeiro ano de uso e, com o aumento da idade uma, aplicou-se uma taxa anual de redução da quilometragem igual à $2 \%$. Os fatores de deterioração para $\mathrm{CO}$ e $\mathrm{HC}$, foram os mesmos da classe AUTO.

Para a classe de motocicletas (MOTO), considerou-se que todos estes veículos eram movidos a gasolina, nacionais e com motor igual ou menor que 150 cilindradas. A quilometragem média anual percorrida por motocicletas novas (em 2013) foi de $12.000 \mathrm{~km}$ no primeiro ano de uso com taxa anual de redução da quilometragem acumulada de $2 \%$ ao ano. Os fatores de deterioração para $\mathrm{CO}$ e $\mathrm{HC}$ foram os mesmos da classe AUTO. 


\section{RESULTADOS E DISCUSSÃO}

A Tabela 2 apresenta o total de veículos e a distribuição deles por classe utilizando dados de 2013 e a Tabela 3 apresenta a distribuição de veículos por faixa etária baseando-se em número de veículos registrados em cada período.

Tabela 2 - Total de veículos e a distribuição da frota de Manaus por classe de veículo no ano

\begin{tabular}{ccc}
\multicolumn{3}{c}{ de 2013.} \\
\hline CLASSE DE VEÍCULO & $\mathbf{N}^{\circ}$ DE VEÍCULOS & $\mathbf{\%}$ \\
\hline AUTO & 311.179 & 53,54 \\
CL & 94.318 & 16,23 \\
VP & 40.156 & 6,91 \\
MOTO & 135.526 & 23,32 \\
TOTAL & $\mathbf{5 8 1 . 1 7 9}$ & $\mathbf{1 0 0 , 0}$ \\
\hline
\end{tabular}

Tabela 3 - Distribuição da frota de Manaus por faixa etária baseando-se em número de veículos registrados em cada período.

\begin{tabular}{ccc}
\hline FAIXA ETÁRIA & $\mathbf{N}^{\circ}$ DE VEÍCULOS & $\mathbf{\%}$ \\
\hline PRÉ-1957 & 644 & 0,11 \\
$1957-1963$ & 156 & 0,03 \\
$1964-1973$ & 3.576 & 0,62 \\
$1974-1983$ & 25.665 & 4,42 \\
$1984-1993$ & 42.186 & 7,26 \\
$1994-2003$ & 125.456 & 21,59 \\
2004-2013 & 383.496 & 65,99 \\
TOTAL & $\mathbf{5 8 1 . 1 7 9}$ & $\mathbf{1 0 0 , 0 0}$ \\
\hline
\end{tabular}

Os dados da Tabela 2 mostram que 53,54\% (311.179 veículos) da frota de Manaus era composta de automóveis (AUTO). Deste total, cerca de 36,5\%, 6,06\% e 57,44\% eram movidos a gasolina, a álcool e bicombustível, respectivamente. Dessa forma, nota-se a escolha da população de Manaus pelos automóveis bicombustível, devido à facilidade de poder optar pelo combustível.

A classe de comerciais leves (CL) representava 16,23\% da frota de Manaus, totalizando 94.318 veículos, dos quais cerca de: $34,27 \%$ são a gasolina; $4,33 \%$ a álcool; $34,46 \%$ bicombustível (flex) e; $26,93 \%$ a diesel.

A Tabela 3 mostra como a frota veicular de Manaus cresceu a cada década desde 1957. Em 2013, a maior parte frota de Manaus era composta por veículos que tinham até 10 anos de uso (65,99\%). Entre 2003 e 2013 a frota veicular triplicou, aumentando de 125.456 veículos em 2003 para 383.496 veículos em 2013. No entanto, ainda havia 34,01\% de veículos com mais de 10 anos de uso em circulação. Assim, destaca-se que a renovação da frota veicular é importante para minimizar a emissão de poluentes veiculares para a atmosfera, pois a deterioração da frota aumenta com a sua idade e, consequentemente, a quantidade de poluentes veiculares emitidos também aumenta. 
A Tabela 4 apresenta os resultados das estimativas das taxas de emissão anuais para a classe AUTO.

Tabela 4 - Estimativas das taxas de emissão anuais para a classe AUTO.

\begin{tabular}{ccccc}
\hline TIPO DE COMBUSTÍVEL & \multicolumn{4}{c}{ TAXAS DE EMISSÃO } \\
& (ton/ano) \\
\hline & CO & HC & NOX & RCHO \\
Gasolina & 11.294 & 30 & 4.274 & 16,4 \\
Etanol & 3.707 & 3.909 & 351 & 25 \\
Biocombustível & 1.360 & 1.978 & 1.978 & 6 \\
TOTAL & $\mathbf{1 6 . 3 6 1}$ & $\mathbf{5 . 9 1 7}$ & $\mathbf{6 . 6 0 3}$ & $\mathbf{4 7 , 4}$ \\
\hline
\end{tabular}

Os resultados para a classe de automóveis movidos a gasolina representaram 69,03\% e $64,73 \%$ das emissões de CO e NOx, respectivamente. Além disso, os automóveis movidos a álcool foram responsáveis por $66,06 \%$ e $52,74 \%$ das emissões de $\mathrm{HC}$ e RCHO, respectivamente. Essas taxas de emissão são explicadas devido à grande quantidade de automóveis que utilizam álcool ou gasolina como combustível.

A Tabela 5 apresenta os resultados das estimativas das taxas de emissão anuais para a classe CL.

Tabela 5 - Estimativas das taxas de emissão anuais para a classe CL.

\begin{tabular}{cccccc}
\hline TIPO DE COMBUSTÍVEL & \multicolumn{5}{c}{ TAXAS DE EMISSÃO } \\
& CO & HC & NOX & RCHO & MP \\
& 1.426 & 178 & 140 & 2,4 & -- \\
Gasolina & 6 & 2 & 1,7 & 0,1 & -- \\
Etanol & 386 & 92,5 & 44,4 & 2 & -- \\
Bicombustível & 79 & 217 & 211,4 & -- & 17,5 \\
Diesel & $\mathbf{1 . 8 9 7}$ & $\mathbf{4 8 9 , 5}$ & $\mathbf{3 9 7 , 5}$ & $\mathbf{4 , 5}$ & $\mathbf{1 7 , 5}$ \\
TOTAL & & & &
\end{tabular}

Para a classe de comerciais leve, os veículos movidos a gasolina foram os principais contribuintes para a emissão de poluentes, sendo responsáveis por 75,17\%,60,51\% e 53,44\% das emissões de $\mathrm{CO}, \mathrm{HC}$ e $\mathrm{RCHO}$, respectivamente. Com relação à emissão de $\mathrm{NOx}$, os comerciais leves movidos a diesel contribuíram com 53,18\% das emissões.

A Tabela 6 apresenta os resultados das estimativas das taxas de emissão anuais para a classe VP e MOTO. 
Tabela 6 - Estimativas das taxas de emissão anuais para as classes VP e MOTO.

\begin{tabular}{ccccc}
\hline TIPO DE COMBUSTÍVEL/CLASSE & \multicolumn{4}{c}{ TAXAS DE EMISSÃO } \\
& (ton/ano) \\
\hline & CO & HC & NOx & MP \\
Gasolina / MOTO & 1.829 & 379 & 118 & -- \\
Diesel / VP & 2.000 & 405 & 9.347 & 196 \\
\hline
\end{tabular}

A classe de motocicletas apresentou significativa emissão de poluentes quando comparada às outras classes, o que se deve à grande quantidade deste tipo de veículo em Manaus (representava 23,32\% da frota em 2013). Por exemplo, a emissão de CO por motocicletas (1.829 ton/ano) era maior que a emissão deste poluente pelos comerciais leves movidos a gasolina e quase $10 \%$ da emissão de CO por automóveis movidos a gasolina.

Dentre todas as classes, aquela que apresentou a maior emissão de NOx foi a de veículos pesados, indicando que a utilização de diesel em motores destes veículos favoreceu a formação deste poluente. Para comparação, a emissão de NOx por veículos pesados foi cerca de 23,5 vezes superior à de comerciais leves que utilizaram diesel. Além disso, as emissões de $\mathrm{CO}$ por veículos pesados também foram consideráveis, sendo em torno de $12 \%$ igual à mesma emissão por automóveis. combustível.

A Tabela 7 apresenta a distribuição da frota veicular de Manaus por tipo de

Tabela 7 - Distribuição da frota de Manaus por tipo de combustível no ano de 2013.

\begin{tabular}{ccc}
\hline TIPO DE COMBUSTÍVEL & $\mathbf{N}^{\circ}$ DE VEÍCULOS & $\mathbf{\%}$ \\
\hline GASOLINA & 281.922 & 48,51 \\
ÁLCOOL & 22.829 & 3,93 \\
BICOMBUSTÍVEL & 210.876 & 36,28 \\
DIESEL & 65.552 & 11,28 \\
TOTAL & $\mathbf{5 8 1 . 1 7 9}$ & $\mathbf{1 0 0 , 0 0}$ \\
\hline
\end{tabular}

A distribuição da frota por tipo de combustível mostra que cerca de metade da frota de Manaus apresenta veículos com motores movidos apenas a gasolina. Por outro lado, os dados mostram que desde que os veículos bicombustíveis entraram no mercado, em 2003, a quantidade destes aumentou significativamente, de modo que em 2013 representava $36 \%$ da frota veicular de Manaus, aproximadamente.

A Tabela 8 apresenta a taxa de emissão de poluentes por classe de veículo, considerando a quantidade de veículos em cada classe (dado na Tabela 2). 
Tabela 8 - Taxa de emissão de poluentes por classe de veículo

\begin{tabular}{cccccc}
\hline CLASSE DE VEÍCULO & \multicolumn{5}{c}{ TAXAS DE EMISSÃO } \\
& (kg/ano/veículo da classe) \\
\hline & CO & HC & NOX & RCHO & MP \\
AUTO & 52,58 & 19,01 & 21,22 & 0,15 & -- \\
CL & 20,11 & 3,12 & 4,21 & 0,05 & 0,19 \\
VP & 49,81 & 10,09 & 232,77 & -- & 4,88 \\
MOTO & 13,50 & 2,80 & 0,87 & -- & -- \\
\hline
\end{tabular}

Os resultados da Tabela 8 mostram que cada veículo pesado (VP) e cada automóvel de Manaus emitem 232,77 e $19 \mathrm{~kg}$ por ano de $\mathrm{NO}_{\mathrm{X}}$ e $\mathrm{HC}$, respectivamente. A emissão destes compostos para a atmosfera associada à presença de terpenos da floresta amazônica podem provocar poluição atmosférica em Manaus, contribuindo para a formação de névoa fotoquímica com presença de aerossóis e formação de ozônio troposférico e provocando problemas ao meio ambiente e à saúde da população.

Além disto, a emissão dos poluentes apresentados na Tabela 8 podem agravar problemas de poluição atmosférica em períodos de seca na região de Manaus (período de junho a novembro), quando a incidência de radiação ultravioleta e a presença de queimadas são maiores.

\section{CONCLUSÃO}

Em 2013, a frota veicular de Manaus era composta por cerca de 53\% de automóveis, $23 \%$ de motocicletas e $24 \%$ de veículos pesados e comerciais leves, sendo que $66 \%$ desta frota era de veículos com até 10 anos de uso. Além disso, 48,5\% da frota era composta por veículos com motor a gasolina e 36\% com motor bicombustível (que usa álcool ou gasolina).

As taxas de emissão por unidade de veículo de cada classe indicaram que as classes automóveis (AUTO) e veículos pesados (VP) foram as que mais contribuíram para a poluição veicular em Manaus.

Os resultados deste inventário fornecem informações úteis para implementação de políticas públicas para monitoramento e controle da qualidade do ar.

Vale ressaltar que as taxas de emissão calculadas neste inventário foram estimativas utilizando a abordagem bottom-up, que podem ser comparadas com amostragens de campo e utilizadas como dados de entrada em softwares de dispersão de poluentes atmosféricos.

\section{AGRADECIMENTOS}

À Fundação de Amparo à Pesquisa do Estado do Amazonas - FAPEAM. À Universidade do Estado do Amazonas - UEA 


\section{REFERÊNCIAS}

ANFAVEA - ASSOCIAÇÃO NACIONAL DOS FABRICANTES DE VEÍCULOS AUTOMOTORES. Anuário da Indústria Automobilística Brasileira 2013. Disponível em: <http://www.anfavea.com.br/anuario.html>. Acesso em: ago. 2014.

BAIRD, C. Química Ambiental. 2 ed. Porto Alegre, Bookman.

CARVALHO JÚNIOR, J. A.; LACAVA, P. T. Emissões em processos de combustão. São Paulo: UNESP, 2003.

Cetesb (SÃO PAUlO). Emissões Veiculares no Estado de São Paulo 2013. 2014. Disponível em: $<$ http://www.cetesb.sp.gov.br/ar/emissao-veicular/48-relatoriosepublicacoes>. Acesso em: jan. 2015.

DENATRAN - DEPARTAMENTO NACIONAL DE TRÂNSITO. Frota de Veículos, Frota Nacional (Dezembro de 2013), 03 - Frota por Município. Disponível em: $<$ http://www.denatran.gov.br/frota2013.htm>. Acesso em: ago. 2014. 2014.

EEA - European Environment Agency. Atmospheric Emission Inventory Guidebook, $3^{\mathrm{a}}$ ed. 2003.

EMEP - European Monitoring and Evaluation Programme. EMEP/CORINAIR Atmospheric Emission Inventory Guidebook. 2007.

ONURSAL, B.; GAUTAM. S. P. World Bank Technical Paper. N. 373. 1997.

SHER, E. Handbook of Air Pollution from Internal Combustion Engines: Pollutant Formation and Control. Academic Press. 1998.

UEDA, A. C. Estudo de Compostos Orgânicos Voláteis na Atmosfera da Região Metropolitana de Campinas. Campinas: Faculdade de Engenharia Química, Universidade Estadual de Campinas, 2010. 256 p. Tese (Doutorado).

U.S. EPA (U.S. Environmental Protection Agency) Handbook for criteria pollutant inventory development: a beginners's guide for point and area sources. 1999.

U.S. EPA (U.S. Environmental Protection Agency) Introduction to stationary point source emission inventory development. 2001. 